\title{
Nuevas perspectivas para el tratamiento de la infección por Helicobacter pylori
}

\section{New perspectives in the treatment of Helicobacter pylori infection}

\author{
Bernardita Velasco 1 , Cynthia Durán', Tania F. Bahamondez-Canas ${ }^{1,2^{*}}$
}

\section{Resumen}

La infección por Helicobacter pylori es altamente prevalente en el mundo. En Chile, esta bacteria está presente entre un 40-70\% de la población y su presencia está asociada a serias complicaciones que van desde la gastritis y el desarrollo de úlceras hasta el cáncer gástrico. Este último, es uno de los carcinomas más frecuentes en nuestro país, con una tasa de mortalidad de 20 por cada 100000 habitantes. Actualmente, el principal tratamiento de erradicación de esta bacteria se basa en triterapias, que consisten en un inhibidor de la bomba de protones (IBP) asociado a dos antibióticos en altas dosis. Sin embargo, existe una gran resistencia de H. pylori a los antibióticos, que ha sido reportada por la literatura científica y reconocida por la Organización Mundial de la Salud (OMS). Esta revisión se enfoca en identificar nuevas estrategias de tratamiento para la erradicación de $H$. pylori con especial interés en aquellos tratamientos que han sido evaluados contra el crecimiento de este patógeno en forma de biopelículas. Este tipo de crecimiento le confiere a $H$. pylori una mayor resistencia a los antibióticos. Se analizaron diferentes agentes y formulaciones que han sido reportados. Se destacan el uso de nanopartículas y compuestos naturales, así como formulaciones bioadhesivas que han mostrado disminuir la infección por $H$. pylori. Sin embargo, se sigue necesitando avanzar en estudios clínicos para comprobar la eficacia de nuevas formulaciones con miras a una exitosa erradicación de H. pylori.

Palabras clave: Helicobacter pylori; infección; erradicación; biopelículas; tratamiento.

\begin{abstract}
Helicobacter pylori infection is highly prevalent worldwide. In Chile, about 40 to $70 \%$ of the population is infected with this pathogen. $H$. pylori infection is linked with severe complications ranging from gastritis and ulcer development to gastric carcinoma. The latter is one of the most frequent cancers in our country, with a mortality of 20 per 100000 people. The primary eradication treatment for this infection is a tritherapy comprised of a proton pump inhibitor combined with two antibiotics at high doses. However, there is a great resistance of $\mathrm{H}$. pylori to antibiotics, reported by the literature and recognised by the World Health Organization (WHO). This review focuses on identifying novel strategies for eradicating $\mathrm{H}$. pylori with a particular interest in those treatments that have been tested against $H$. pylori growing in the form of biofilms. This type of microbial growth provides high resistance to antibiotics. We analysed different agents and formulations reported in the literature. Nanoparticles and natural compounds, as well bioadhesive formulations, are among the treatments showing promising results in reducing the infection. However, more clinical studies are needed to validate the efficacy of these novel treatments to successfully eradicate $H$. pylori.
\end{abstract}

Keywords: Helicobacter pylori; infection; eradication; biofilms; treatment.

Fecha de envío: 2021-06-01 - Fecha de aceptación: 2021-08-24

\section{Introducción}

Helicobacter pylori es una de las bacterias patógenas más prevalentes a nivel mundial, afectando a un 50\% de la población (Ortega et al., 2010). En Chile, esta bacteria está presente en un 73\% en pacientes adultos asintomáticos y su tratamiento farmacológico empírico se basa en el uso de claritromicina, amoxicilina e inhibidor de la bomba de protones (IBP), aun cuando existe una tendencia al aumento de resistencia a claritromicina sobre el 20\% (Arenas

(1) Escuela de Química y Farmacia, Facultad de Farmacia, Universidad de Valparaíso, Valparaíso, Chile.

(2) Centro de Investigación Farmacopea Chilena, Universidad de Valparaíso, Valparaíso, Chile.

*Autor de correspondencia: tania.bahamondez@uv.cl 
et al., 2019). A pesar que un $85 \%$ de las personas que se contagia con $\mathrm{H}$. pylori no presentan síntomas o tienen gastritis leve, el $15 \%$ tiene la probabilidad de desarrollar úlcera péptica en el largo plazo y aproximadamente el $1 \%$ podría desarrollar cáncer gástrico como el linfoma gástrico del tejido linfoide asociado a mucosa (MALT) y adenocarcinoma (García \& García-González, 2015).

\section{Mecanismos de adaptación y patogenicidad de Helicobacter pylori}

H. pylori es una bacteria gram negativa con forma de espiral y microaerófila que presenta una membrana exterior con 4 a 8 flagelos monopolares cubiertos por lípidos y que infecta comúnmente el tejido gástrico (Figura 1). Los flagelos están compuestos por múltiples subunidades proteicas y tienen como función el transporte, ensamblaje, fijación, rotación, fuerza de impulso y protección del microorganismo. H. pylori ingresa al tubo digestivo desde la vía oral, hasta llegar a la superficie de las células del epitelio gástrico, principalmente a la mucosa gástrica del fundus y del antro pilórico (García \& García-González, 2015). Para poder sobrevivir en el medio ácido del ambiente gástrico, H. pylori expresa la enzima ureasa. Esta enzima cataliza la hidrólisis de la urea en amonio y gas carbónico, generando un $\mathrm{pH}$ neutro alrededor del patógeno. Esta hidrólisis causa una inhibición de los transportadores de bicarbonato en el epitelio gástrico del hospedero y, como consecuencia, la alcalinización de la mucosa gástrica. Por otro lado, se plantea que $H$. pylori bloquea la acción de la enzima $\mathrm{H}+/ \mathrm{K}+-$ ATPasa, disminuyendo así la producción de ácido.

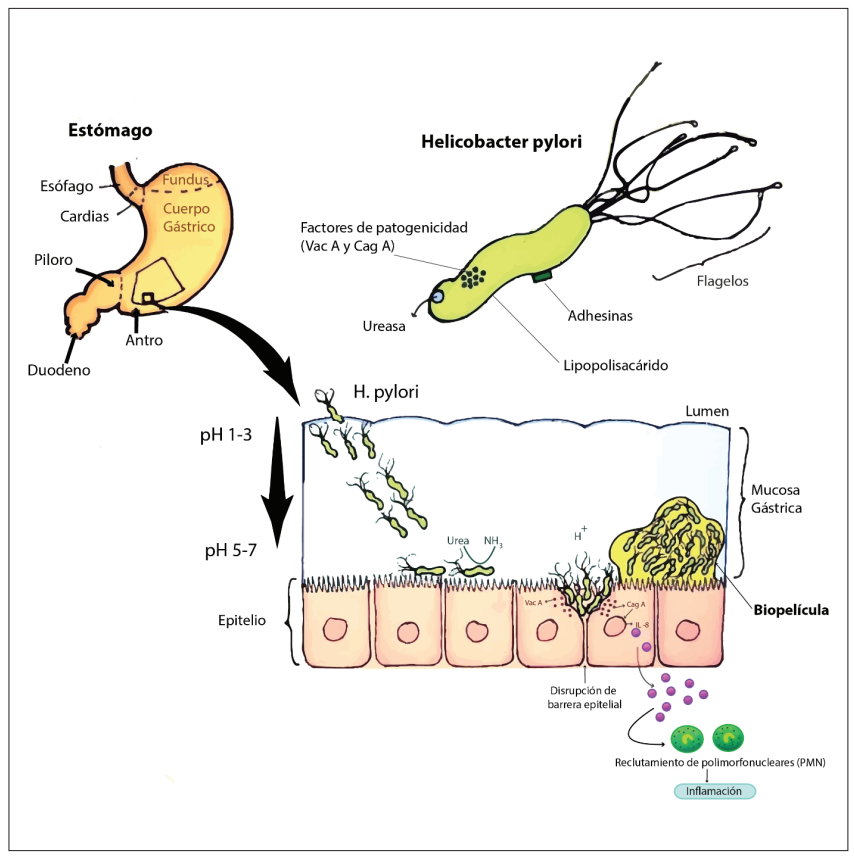

Figura 1: Interacción de Helicobacter pylori con la mucosa gástrica.
La adherencia de $H$. pylori al epitelio gástrico también es relevante para sobrevivir en este ambiente ácido y evitar su arrastre por movimientos peristálticos y por el recambio del moco gástrico. La adhesión a la pared gástrica la consigue a través de múltiples adhesinas y receptores que varían según la expresión de glucanos en la superficie del epitelio, entre las que se destacan BabA, SabA, homB y OipA. Por lo tanto, juegan un papel importante en la cronicidad de la infección (García \& García-González, 2015).

H. pylori expresa diversos factores de patogenicidad como las proteínas VacA y CagA (Figura 1). El gen VacA produce una citotoxina que causa daño celular en el epitelio gástrico. Este daño se debe al aumento de la permeabilidad a aniones orgánicos y a la urea (sustratos esenciales para la acción de la ureasa) mediante la formación de canales dependientes de voltaje en la membrana plasmática de la célula epitelial. H. pylori también expresa el gen CagA que codifica a la proteína oncogénica CagA. Esta proteína altera las vías de transducción de las células epiteliales gástricas y produce inflamación crónica al interactuar con múltiples moléculas de las células del organismo. CagA favorece la aparición del cáncer gástrico mediante un efecto modulador de la apoptosis, la alteración de la polaridad celular y la promoción de la inestabilidad genética (Suriani et al., 2008).

\section{Diagnóstico de la infección por $\boldsymbol{H}$. pylori}

La confirmación de la infección por H. pylori se basa principalmente en la detección de la actividad de la enzima ureasa y en el análisis histológico de biopsias gástricas (Chahuán et al., 2020). El test de la ureasa se basa en la detección de los productos de la hidrolisis de la urea, actuando como un método indirecto de detección de la infección. La prueba de la reacción en cadena de la polimerasa (PCR) también permite diagnosticar la infección al detectar genes característicos de esta bacteria, por lo tanto, representa un método directo de detección con alta sensibilidad y especificidad. Tanto la prueba de la ureasa, el análisis histológico y la PCR requieren de biopsias gástricas como muestra. Por otro lado, para la confirmación de la erradicación postratamiento antibiótico se pueden usar pruebas no invasivas como la detección de antígeno en deposiciones.

\section{Formación de biopelículas y su relación con la cronicidad de las infecciones}

Desde su identificación, los estudios en H. pylori se han basado en su crecimiento unicelular flotante (también conocido como planctónico). Sin embargo, evidencia reciente confirma el crecimiento de H. pylori en forma de biopelículas en la mucosa gástrica (Carron et al., 2006; Coticchia et al., 2006). Las biopelículas son comunidades microbianas que crecen aglomeradas dentro de una matriz 
polimérica que se adhiere a superficies bióticas y abióticas. La bacterias en biopelículas se encuentran protegidas por esta matriz contra la acción de antimicrobianos y factores medioambientales (Donlan \& Costerton, 2002). Si bien las infecciones por biopelículas son muy difíciles de erradicar, no afectan a todas las personas por igual. Se consideran que diversos factores pueden predisponer a la cronicidad de las infecciones, como lo son la edad o la presencia de otras enfermedades basales.

Las biopelículas son la principal forma de crecimiento bacteriano en la naturaleza. Desde los años 80 , se ha acumulado importante evidencia de la presencia de biopelículas en infecciones como las del tracto urinario y de heridas crónicas, que tienen como características común la persistencia y la inflamación crónica (Figura 2). Se ha planteado que las biopelículas contribuyen a la inflamación crónica al ser resistentes a la respuesta inmune, lo que resulta en un reclutamiento constante de células inmunitaria y secreción de enzimas, que contribuye a generar mayor daño al tejido. Si bien los agentes antimicrobianos y la respuesta inmune pueden ser efectivos contra bacterias superficiales de la biopelícula, las bacterias sobrevivientes en regiones más profundas pueden repoblar la biopelícula postratamiento antibiótico (Donlan \& Costerton, 2002).

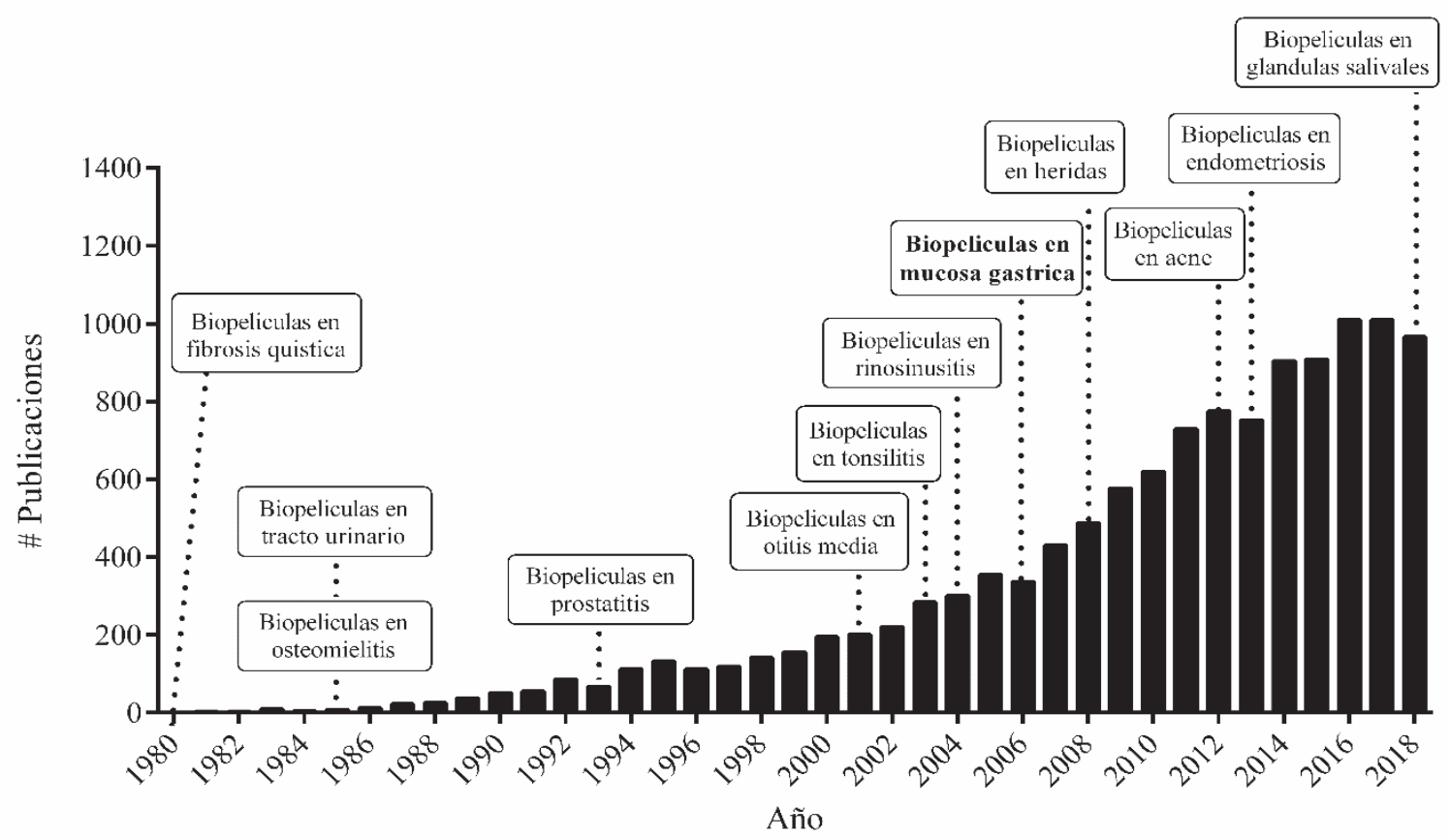

Figura 2: Número de publicaciones por año con la palabra biofilm (biopelícula) en el título del artículo de acuerdo a la búsqueda en Google Académico. Las etiquetas destacan las fechas en que se reportó evidencia de biopelículas en nuevos tejidos e infecciones. Figura traducida de Bahamondez-Canas et al. (2019).

Se han descrito microambientes heterogéneos dentro de las biopelículas que difieren en la concentración de oxígeno y nutrientes, y que pueden inducir distintos estados metabólicos. A la subpoblación microbiana que se encuentra en un estado metabólico mínimo o durmiente se les conoce como bacterias persistentes (Holden, 2015). Estas bacterias persistentes han sido apuntadas como las principales responsables de la recurrencia de las infecciones por biopelículas, ya que este estado les permite sobrevivir a aquellos tratamientos cuyo mecanismo de acción se basa en impedir actividades como la síntesis de proteínas o replicación celular. Por lo tanto, las bacterias "persistentes" difieren de las "resistentes" en que estás últimas presentan una resistencia a los antibióticos estable en el tiempo mientras que las primeras tienen una respuesta tolerante transitoria o reversible. Es decir, las bacterias persistentes pueden salir desde este estado una vez modificadas las condiciones ambientales, como, por ejemplo, al terminar el tratamiento antibiótico. En la figura 3 se representa una biopelícula genérica en donde se identifican componentes principales de la matriz extracelular y se refleja la diversidad fenotípica y genotípica que puede albergar una biopelícula. 


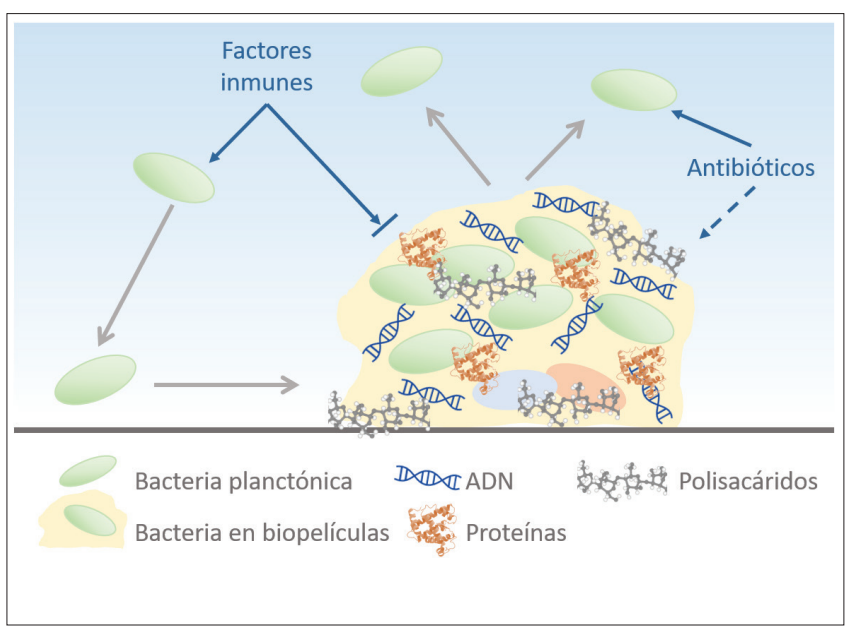

Figura 3: Esquema de una biopelícula bacteriana. Las bacterias verdes representan aquellas que son susceptibles a los antimicrobianos (también conocidas como silvestres o wild-type). Las bacterias rojas son aquellas resistentes y las azules son las tolerantes o persistentes. Se postula que las bacterias persistentes serían las principales responsables de la amplia resistencia antibiótica desplegada por las biopelículas, al actuar como reservorio de bacterias viables con potencial de resurgir postratamiento.

\section{Biopelículas de Helicobacter pylori}

Si bien se tiene conocimiento de la infección por $H$. pylori desde principios de la década de los ochenta, no fue hasta el 2006 en que se evidenciaron biopelículas en biopsias de mucosa gástrica. Carron et al. (2006) fueron los primeros en reportar su presencia, seguidos de Coticchia et al. (2006) quienes observaron una alta correlación entre la presencia de biopelículas y la positividad de la prueba de la ureasa, evidenciado que esta forma de crecimiento sería más bien predominante que anecdótica. Complementariamente, se ha podido caracterizar la alta tolerancia a los antibióticos de estas biopelículas y el rol estructural de sus flagelos a través del estudio de cultivos in vitro (Yonezawa et al., 2013; Hathroubi et al., 2020). Por lo tanto, la formación de biopelículas podría aportar una explicación alternativa a la persistencia de estas infecciones junto a los mecanismos de adaptación al medio gástrico descritos anteriormente.

\section{Resistencia antimicrobiana de Helicobacter pylori}

Se ha demostrado que el crecimiento de H. pylori en forma de biopelículas le confiere resistencia contra varios antibióticos. El uso de proteinasas aumentaría la eficacia de claritromicina contra $H$. pylori al alterar la integridad de la matriz de las biopelículas e inducir su dispersión (Hathroubi et al., 2020). Estos antecedentes se suman a los mecanismos de resistencia a claritromicina y levofloxacino ya conocidos, como la mutación del gen ARNr 23S y del gen gyrA, respectivamente (Yonezawa et al., 2013; Arenas et al., 2019; González-Hormazábal et al., 2021). Además, el microambiente en la biopelícula favorece la comunicación bacteriana por proximidad, pudiendo intercambiar material genético de los plásmidos (Donlan $\&$ Costerton, 2002). Se ha reportado que la resistencia a claritromicina es mucho más frecuente que en su crecimiento planctónico (Yonezawa et al., 2013). Por lo tanto, la resistencia desplegada por H. pylori sería resultado tanto de la protección física y de la aumentada transmisión de genes de resistencia en las biopelículas.

Considerando estos antecedentes, el objetivo de este manuscrito es revisar nuevas estrategias de tratamiento para la erradicación de H. pylori, repasando los esquemas de tratamientos convencionales, para luego analizar los tratamientos alternativos que han sido reportados en la literatura científica con especial enfoque en aquellos con eficacia contra biopelículas de $H$. pylori.

\section{Tratamiento de la infección por Helicobacter pylori}

Los tratamientos comúnmente utilizados incluyen un IBP, claritromicina, amoxicilina, metronidazol y sales de bismuto. Es importante considerar los factores que influyen en la elección del tratamiento para la erradicación de $H$. pylori, ya que de esto dependerá el éxito terapéutico. La terapia farmacológica es particular según cada paciente y según la zona geográfica en donde se encuentre, ya sea, continente, país, región o ciudad.

\section{a. Tratamientos convencionales}

En general, el tratamiento en la práctica clínica es empírico basado en recomendaciones de diversos consensos de expertos que analizan la evidencia científica para actualizar estos esquemas. Se destacan el Consenso de América Latina (2014), el Consenso de Maastricht V/Florence (2016) y el Consenso IV Conferencia Española (2016). Estas recomendaciones de tratamiento se agrupan en diferentes esquemas farmacológicos según cada país.

Para nuestro país, se recomienda como primera línea cuadriterapia con bismuto o la cuadriterapia concomitante (IBP, amoxicilina, claritromicina y metronidazol). Cuando este tratamiento fracasa, la segunda línea se prosigue con cuadriterapia basada en bismuto (reemplazando amoxicilina por tetraciclina). De fracasar con la segunda línea, se recomienda efectuar pruebas de sensibilidad microbiana (Villalón et al., 2020). En la tercera línea, se recomienda no utilizar los mismos fármacos administrados en los regímenes previos. Como alternativa se puede utilizar una terapia cuádruple con levofloxacina basada en bismuto (Flores-Treviño et al., 2018). En pacientes alérgicos a las penicilinas, se recomienda la terapia cuádruple con bismuto, que incluye IBP, bismuto, metronidazol y tetraciclina. De fracasar, se prosigue con triterapia o cuadriterapia con levofloxacino (Villalón et al., 2020). 
Por otro lado, la Asociación de Gastroenterología Americana (AGA) actualizó la práctica clínica para los pacientes con refractariedad a la infección. Refractariedad es definida como un resultado persistente de una prueba positiva a H. pylori (no serológica) por al menos cuatro semanas después de una o más terapias de erradicación. En esta situación, AGA sugiere los siguientes esquemas farmacológicos descritos como PAR (IBP, amoxicilina, y rifabutina), PAL (IBP, amoxicilina y levofloxacino) o PBLA (IBP, bismuto, levofloxacino y amoxicilina). La aplicación de estos esquemas se condiciona a contar con una resistencia a levofloxacino menor al 15\%, usar altas dosis de amoxicilina e IBP (alta dosis o alta potencia) y a la disponibilidad de la rifabutina. En caso de pacientes alérgicos a penicilina, se utiliza tetraciclina o metronidazol en lugar de amoxicilina. Claritromicina es otra alternativa sólo si la cepa es sensible. Si existe una falla en estos esquemas se recomienda realizar pruebas de sensibilidad antes de continuar con una terapia dual en altas dosis, que consiste en la administración de 2-3 g, divididos en tres tomas diarias de amoxicilina más un IBP, con el propósito de evitar la disminución de las concentraciones plasmáticas del fármaco para aumentar su eficacia (Shah et al., 2021). Finalmente, cabe destacar que amoxicilina, tetraciclina y rifabutina presentan resistencias muy bajas, por tanto, se pueden volver a repetir en los diferentes esquemas, ya sea desde la segunda línea en adelante (Shah et al., 2021).

Si bien sigue siendo difícil de implementar en la práctica, múltiples autores coinciden en enfatizar la importancia de realizar pruebas de sensibilidad antimicrobiana para la definición del tratamiento a seguir. La revisión de Martínez et al. (2014) identifica la prueba de dilución en agar y el e-test como las más frecuentemente utilizadas en América Latina. Estas pruebas permiten determinar la concentración mínima inhibitoria (CMI), el indicador más usado para comparar la resistencia de los aislados clínicos. De este modo, el grupo reportó la mayor resistencia para metronidazol (66\%) y levofloxacino (39\%), seguido de claritromicina (14\%) y tetraciclina, furazolidona y amoxicilina (<10\%) (Martínez et al., 2014) Cabe destacar la prueba PCR, mencionada anteriormente, ya que permite identificar la presencia de genes de resistencia. Considerando el aumento de la implementación de esta técnica en el contexto de la pandemia por SARS-CoV-2, se podría prever su mayor aprovechamiento diagnóstico en el futuro.

\section{a. Otros fármacos}

El antimicrobiano rifabutina es un inhibidor de la síntesis de proteínas con un amplio espectro que incluye actividad contra micobacterias, bacterias grampositivas y gramnegativas y protozoos (Toxoplasma gondii). Se puede utilizar rifabutina junto con amoxicilina, tetraciclina y esomeprazol en zonas de multirresistencia a claritromicina, metronidazol y levofloxacino, en donde se ha fracasado con otras terapias. En estos pacientes la tasa de recuperación fue de un $83 \%$ (Argueta \& Moss, 2019). A pesar de esta evidencia, su uso es reducido ya que no se encuentra disponible en todo el mundo. En Chile, la rifabutina no se encuentra registrada en el ISP. Es mencionada en la guía clínica del síndrome de inmunodeficiencia adquirida (VIH/SIDA) como alternativa en el tratamiento de la tuberculosis, sin embargo, la misma guía confirma que no está disponible en nuestro país (MINSAL, 2013).

Por otro lado, se ha utilizado vonoprazan, un potente IBP empleado en Japón (Shinmura et al., 2019). Siendo de acción más rápida, más potente $y$ al no requerir ser activado previamente, tiene una vida media más prolongada. La evidencia de su eficacia y su uso en la erradicación de $H$. pylori, se limita a Japón y otros países de Asia, por lo tanto, se necesitan más estudios en diferentes poblaciones para poder incluir este fármaco a las terapias con antibióticos.

\section{b. Probióticos}

Es sabido que los tratamientos antibióticos pueden generar un desequilibrio en la microbiota gastrointestinal y que los probióticos tienen un efecto protector competitivo contra microorganismos patógenos (Kamiya et al., 2019). A los probióticos se les atribuyen distintos mecanismos de acción, como la inhibición de la colonización y la adhesión de H. pylori, así como también la disminución de la inflamación (Hu et al., 2020). Se ha demostrado que la suplementación con Lactobacillus gasseri, Lactobacillus casei, Lactobacillus acidophilus, Lactobacillus reuteri y $G G)$ puede mejorar significativamente la tasa de erradicación durante el tratamiento con triterapia convencional (Yu et al., 2019). Similarmente, se demostró un aumento en la efectividad de la terapia cuádruple al administrar cepas probióticas de Bifidobacterias (Jiang \& Zhu, 2018). También se ha demostrado in vitro el potencial bacteriostático y bactericida de cinco cepas probióticas sobre H. pylori (L. casei, L. paracasei, L. acidophilus, Bifidobacterium lactis y Streptococcus thermophilus) (Saracino et al., 2020). El sobrenadante de cultivo de probióticos (L. plantarum) también fue capaz de erradicar biopelículas maduras de H. pylori in vitro (Ji \& Yang, 2021), indicando que los cultivos probióticos pueden también ser fuente de compuestos anti- $H$. pylori. Es necesario sustentar esta evidencia con estudios clínicos que permitan validar tanto su uso como determinar las cepas y su posología.

\section{Tratamientos alternativos y experimentales}

A pesar de la existencia de diversos esquemas de tratamiento, sigue siendo una infección altamente persistente en tiempos en que la resistencia a los antibióticos continua en aumento. En este contexto, por su alta resistencia a la claritromicina, $H$. pylori fue incluido en la lista de patógenos prioritarios para la investigación 
y desarrollo de nuevos antibióticos de la Organización Mundial de la Salud (OMS) en el 2017. Por lo tanto, es necesario desarrollar nuevas estrategias de tratamiento que puedan hacerse cargo de esta infección tan resistente considerando además su forma de crecimiento en biopelículas.

En términos generales, las estrategias antibiopelículas usadas en la actualidad y reportadas en la literatura se pueden clasificar en estrategias preventivas o de erradicación. Estas últimas se pueden subclasificar en 1) uso de agente dispersantes, 2) uso de antibióticos modificados o vehículos que promuevan su difusión a través de la matriz de la biopelícula o la capa mucosa, 3) uso de agentes que reviertan el estado persistente y 4 ) uso de inhibidores de la comunicación bacteriana (inhibidores del quorum sensing). La estrategia 4 se vislumbra como la más promisoria ya que podría permitir modular respuestas microbianas, al prevenir la formación de la biopelícula, inducir su dispersión o inhibir la secreción de citotoxinas, y la vez, prevenir el desarrollo de resistencia. Por otro lado, la estrategia 2 no solo es relevante para su acción contra biopelículas, sino que también permite enfrentar el desafío de entregar activos a través de la barrera representada por la membrana mucosa (Leal et al., 2017).

Por otro lado, también existen estrategias de formulación que apuntan a aumentar el tiempo de retención de los antibióticos en el estómago, lo que se conoce como gastroretención. Estas formulaciones tienen el potencial de aumentar la eficacia de los tratamientos y reducir efectos adversos, al aumentar su biodisponibilidad y reducir tanto la dosis como la frecuencia de las dosis, contribuyendo también a la adherencia a la terapia. Los sistemas de administración gastrorententivos incluyen sistemas flotantes, sistemas mucoadhesivos y sistemas expandibles (Zhao et al., 2014). Los sistemas flotantes logran una mayor permanencia en el estómago al flotar sobre la superficie de su contenido y liberar el principio activo de forma prolongada. Los sistemas mucoadhesivos por otro lado, se adhieren a la superficie de la mucosa gástrica y están constituidos de polímeros bioadhesivos como alginato y quitosano. Finalmente, los sistemas expandibles tienen la capacidad de hincharse por captación de agua y ser retenidos en el estómago en función de su tamaño.

A continuación, se detalla evidencia sobre diferentes agentes y formulaciones propuestos para la erradicación de $H$. pylori que se encuentran en etapas de investigación.

\section{Nanopartículas (NP) y transportadores}

El estudio de las NP se está haciendo cada vez más presente para mejorar los esquemas de tratamiento ya existentes y crear nuevas estrategias terapéuticas. Dado que sus tamaños son reducidos, pueden aumentar la biodisponibilidad del medicamento, eficacia terapéutica, aumentando la focalización en el sitio deseado al ser liberación sostenida, liberación controlada y con gran capacidad de carga del medicamento (Urrejola et al., 2018). Además de sus ventajas, las NP y otros complejos transportadores pueden ser funcionalizados al conjugar en su superficie compuestos que le confieran propiedades antimicrobianas adicionales o propiedades físicas como mucoadhesión o mejor permeabilidad.

Estas estrategias de formulación se han testeado in vitro en forma de NP magnéticas, metálicas y transportadores como liposomas contra H. pylori. Un ejemplo son las NP magnéticas de óxido de hierro super magnético (SPIO) con ácido poliacrílico (PAA) y amoxicilina, con las cuales se forma SPIO/AMO y PAA/quitosano (PAA/CHI) (Tabla 1). Estas NP son resistentes al ácido gástrico, son adhesivas, capaces de penetrar la capa de moco y liberar la amoxicilina en el sitio afectado por H. pylori. Estas NP magnéticas SPIO/AMO y las PAA/ $\mathrm{CHI}$, permiten aumentar el tiempo de residencia gástrica siendo un ejemplo de sistema mucoadhesivo (Yang et al., 2020). Si bien, estas pueden ser eliminadas por el recambio mucoso, la aplicación de un campo magnético permite homogeneizar la distribución del fármaco y mejorar su penetración en biopelículas de H. pylori.

En cuanto a las NP de plata, bismuto, oro, hierro y zinc se ha informado que son bactericidas (incluido H. pylori) a bajas concentraciones, con casi nula posibilidad de crear resistencia antimicrobiana. Esta acción bactericida se logra mediante mecanismos de estrés oxidativo, liberación de iones metálicos y estrés no oxidativo. Las NP de plata podrían inhibir a H. pyloriy su actividad de la enzima ureasa sin tener efecto citotóxico en células de epitelio de adenocarcinoma gástrico (AGS) (Gottesmann et al., 2020) (Tabla 1). Pese a que es una estrategia prometedora para poder disminuir las dosis de antibióticos en las terapias convencionales, se sugiere a la misma vez hacer estudios de los posibles efectos tóxicos que pueden provocar. El estudio de Gopalakrishnan et al. (2020) avanza esta dirección al desarrollar NP de plata conjugadas con enzimas degradadoras de moléculas quorum sensing (QS) a las que también se evaluó su compatibilidad. Estas NP redujeron la formación de biopelículas de $H$. pylori y la producción de ureasa in vitro además de mostrar buena biocompatibilidad. Este es un ejemplo del uso de NP como transportador de inhibidores de la comunicación bacteriana.

Las pectinas de manzana son capaces de inhibir la adhesión de $H$. pylori a células del epitelio gástrico mediada por BabA y lipopolisacaridos. Su uso es económico y biocompatible. Por lo tanto, el recubrimiento de transportadores como los liposomas con pectina de manzana promete un sistema de transporte de fármacos e interacción directa con el sitio de acción y la bacteria (Tabla 1). Gottesmann et al. (2020) desarrollaron estos liposomas recubiertos capaces de liberar el antibiótico encapsulado por erosión de la capa lipídica, bombeo osmótico o difusión y ejerce un efecto directamente sobre H. pylori. Cabe destacar que esta 
estrategia seria efectiva en la prevención y protección de casos recurrentes por el efecto antiadhesivo que presenta al evitar que H. pylori se una al epitelio.

Li et al. (2019) utilizaron fosfolípidos conjugados con polietilenglicol (PEG) para mejorar la permeabilidad y ramnolípidos para potenciar la acción antimicrobiana de NP poliméricas cargadas de claritromicina. El grupo se enfocó en desarrollar NP lipídicas con el fin de atravesar la capa de moco de la mucosa gástrica y alterar la biopelícula de $H$. pylori in vitro. Estás NP presentan un núcleo de quitosano con claritromicina encapsulada, cubierta por una capa lipídica de ramnolípidos. A su vez, para mejorar la hidrofilia se modificó la superficie de la cubierta con DSPE-PEG2000 (fosfolipido pegilado). Los resultados de este estudio demostraron la eficacia de las NP en la erradicación de la biopelícula de H. pylori al reducir significativamente la biomasa y viabilidad, la destrucción de la arquitectura y la eliminación de la matriz polimérica de la biopelícula. Esta formulación es un ejemplo de cómo, a través de la tecnología farmacéutica se permite optimizar el uso de principios activos ya existentes. Además, se destaca su efecto erradicador contra biopelículas de H. pylori.

\section{Otros agentes}

$\mathrm{N}$-acetilcisteína (NAC) es un compuesto derivado del aminoácido cisteína y precursor de la L-cisteína que se utiliza como mucolítico en afecciones bronquiales agudas y crónicas. NAC reduce la viscosidad y grosor del moco en pulmones y superficie gástrica al promover la escisión de enlaces disulfuro de las glicoproteínas del moco. Si bien existen evidencia de su beneficio contra biopelículas in vitro y como pretratamiento antibiótico (Cammarota et al., 2010), su uso concomitante con antibióticos no ha mostrado beneficios clínicos concluyentes. Shen et al. (2020a) evaluaron la actividad de NAC, ramnolípidos y lauril sulfato de sodio sobre biopelículas de diferentes especies bacterianas in vitro. Solo los ramnolípidos, biosurfactantes de origen bacteriano, lograron erradicar las biopelículas de $H$. pylorial actuar desestabilizando la matriz extracelular. Los ramnolípidos además han mostrado sinergismo con claritromicina y amoxicilina (Chen et al., 2019) y con antibióticos naturales (derivados de berberina) (Shen et al., 2020b), siendo excelentes candidatos para su futuro desarrollo como coadyuvantes. Miricetina, un flavonoide, no solo reduciría la formación de biopelículas, sino que aumentaría la eficacia de cinco antibióticos usados convencionalmente en el tratamiento de $H$. pylori (Krzyżek et al., 2021). La evodiamina tendría efecto antibacteriano y antivirulento contra H. pylori (Yang et al., 2021).

Tabla 1: Resumen de los tratamientos experimentales reportados en la literatura científica.

\begin{tabular}{|c|c|c|c|c|}
\hline Compuesto estudiado & Modelo & Esquema / Condiciones experimentales & Resultados & Ref. \\
\hline $\begin{array}{l}\text { NP poliméricas lipídicas } \\
\text { con CLR encapsulada }\end{array}$ & In vitro & $\begin{array}{l}\text { Determinación de biomasa de biopelículas } \\
\text { y la agregación entre NP y mucina. }\end{array}$ & $\begin{array}{l}\text { NP mostraron mejor erradicación comparado a } \\
\text { CLR. Se comprobó la penetración de NP a través } \\
\text { de la capa de moco. }\end{array}$ & (Li et al., 2019) \\
\hline NP SPIO/AMX y PAA/CHI & In vivo & $\begin{array}{l}\text { Pre-infección con } H \text {. pylori tratada con } \\
\text { NP expuestas a campos magnéticos } \\
\text { durante } 30 \text { min. }\end{array}$ & $\begin{array}{l}\text { Tasa de erradicación con NP fue del } 50 \% \text { versus } \\
20 \% \text { con AMX libre y } 60 \% \text { con aplicación de } \\
\text { campo magnético. }\end{array}$ & $\begin{array}{l}\text { (Yang et al., } \\
2020)\end{array}$ \\
\hline $\begin{array}{l}\text { Liposomas recubiertos } \\
\text { en pectina de manzana } \\
\text { con AMX encapsulada }\end{array}$ & In vitro & $\begin{array}{l}\text { Evaluación de mucoadhesión de liposomas, } \\
\text { la interacción entre liposomas y H. pylori } \\
\text { y la liberación in vitro de AMX. }\end{array}$ & $\begin{array}{l}\text { Se demostró la mucoadhesión y penetración } \\
\text { de los liposomas a la mucina, la interacción con } \\
\text { estructuras superficiales de H. pylori y la descarga } \\
\text { del antibiótico. }\end{array}$ & $\begin{array}{l}\text { (Gottesmann et } \\
\text { al., 2020) }\end{array}$ \\
\hline $\begin{array}{l}\text { NP de AHL-lactonasa y } \\
\text { plata }\end{array}$ & In vitro & $\begin{array}{l}\text { Determinación de erradicación y actividad } \\
\text { anti-QS y determinación de biocompa- } \\
\text { tibilidad. }\end{array}$ & $\begin{array}{l}\text { Reducción de biopelículas y producción de ureasa } \\
\text { por degradación de moléculas QS. }\end{array}$ & $\begin{array}{l}\text { (Gopalakrishnan } \\
\text { et al., 2020) }\end{array}$ \\
\hline Ramnolípidos & In vitro & $\begin{array}{l}\text { Determinación de erradicación y sobre- } \\
\text { vivencia de biopelículas en tratamiento } \\
\text { concomitante con AMX, CLR y IBP. }\end{array}$ & $\begin{array}{l}\text { Erradicación de un 95\% en combinación con } \\
\text { AMX + IBP }\end{array}$ & $\begin{array}{l}\text { (Chen et al., } \\
\text { 2019) }\end{array}$ \\
\hline Ramnolípidos & In vitro & $\begin{array}{l}\text { Determinación de CMl en H. pylori y otras } \\
4 \text { especies. }\end{array}$ & Erradicación de biopelículas maduras de H. pylori. & $\begin{array}{l}\text { (Shen et al., } \\
\text { 2020a) }\end{array}$ \\
\hline $\begin{array}{l}\text { NP de berberina y } \\
\text { ramnolípidos }\end{array}$ & $\begin{array}{l}\text { In vitro e } \\
\text { in vivo }\end{array}$ & $\begin{array}{l}\text { Determinación de CMI, erradicación, } \\
\text { viabilidad de biopelículas y permeación } \\
\text { de mucosa }\end{array}$ & $\begin{array}{l}\text { Permeación de barrera mucosa, actividad } \\
\text { bactericida y erradicación de biopelículas }\end{array}$ & $\begin{array}{l}\text { (Shen et al., } \\
\text { 2020b) }\end{array}$ \\
\hline Proteinasa K & In vitro & $\begin{array}{l}\text { Determinación de CMI en combinación } \\
\text { con CLR }\end{array}$ & $\begin{array}{l}\text { Dispersión de biopelícula y disminución de la } \\
\text { CMI de CLR }\end{array}$ & $\begin{array}{l}\text { (Hathroubi et al., } \\
\text { 2020) }\end{array}$ \\
\hline Miricetina & In vitro & $\begin{array}{l}\text { Determinación de CMI solo o en combi- } \\
\text { nación con AMX, CLR, TTC, MTZ y LEV y } \\
\text { cambios morfológicos }\end{array}$ & $\begin{array}{l}\text { Disminución de la CMI de los antibióticos y } \\
\text { reducción de formación de biopelícula. }\end{array}$ & $\begin{array}{l}\text { (Krzyżek et al., } \\
\text { 2021) }\end{array}$ \\
\hline Evodiamina & In vitro & $\begin{array}{l}\text { Determinación de proliferación y } \\
\text { expresión génica }\end{array}$ & $\begin{array}{l}\text { Disminución de la proliferación y de la expre- } \\
\text { sión de CagA y VacA }\end{array}$ & (Yang et al., 2021) \\
\hline
\end{tabular}


AMX: amoxicilina; CLR: claritromicina; NP: nanopartículas; SPIO: óxido de hierro superparamagnético; PAA: ácido poliacrílico; $\mathrm{CHI}$ : quitosano; AGS: adenocarcinoma gástrico; NAC: N-acetilcisteína; CMI: concentración mínima inhibitoria; IBP: inhibidor de bomba de protones; TTC: tetraciclina; MTZ: metronidazole; LEV: levofloxacino.

\section{Perspectivas futuras}

En esta revisión hemos abordado parte de las distintas estrategias terapéuticas que están actualmente siendo desarrolladas para tratar la infección por H. pylori. También revisamos la evidencia que confirma el crecimiento de esta bacteria en forma de biopelículas como un factor adicional que contribuye a su elevada resistencia a los antibióticos (Yonezawa et al., 2013). Por otro lado, a pesar del limitado uso o acceso a pruebas de sensibilidad en la práctica, es importante avanzar en esa dirección considerando el aumento en la resistencia antimicrobiana de H. pylori. La prueba PCR permitiría tanto diagnóstico como detección de resistencia a antibióticos $y$, por su uso más masificado en el contexto de la pandemia por COVID-19 que enfrentamos en la actualidad, se podría prever un mayor aprovechamiento en el futuro. También es importante avanzar de la mano en dilucidar los factores individuales que convierten a H. pylori en un riesgo, ya que se sabe que no afecta a la población por igual, por lo que la estrategia de erradicación universal no está libre de cuestionamientos (Miller \& Williams, 2021).

Los tratamientos analizados abarcan un amplio abanico de estrategias que van desde el estudio de nuevos agentes antimicrobianos, rescatar el potencial de compuestos naturales y antibióticos reconocidos, y la optimización de sus propiedades a través del desarrollo de nanoformulaciones y transportadores funcionalizados con distintos recubrimientos. Se destaca el potencial de las pectinas de manzana y otros inhibidores de la adhesión en prevenir la adhesión de H. pylori y la aplicación de los sistemas gastroretentivos como plataformas versátiles que permiten ser cargados con diferentes activos (Zhao et al., 2014).

\section{Conclusiones}

La infección causada por Helicobacter pylori sigue siendo una preocupación a nivel mundial. El aumento de la resistencia a los antibióticos utilizados en las terapias convencionales como la claritromicina, la capacidad de esta bacteria para evadir el sistema inmune del hospedador y su alta tasa de infección, la han convertido en un patógeno con gran capacidad de adaptabilidad para sobrevivir en el huésped. Además, la confirmación relativamente reciente de su crecimiento en forma de biopelículas, permite explicar en parte su alta persistencia y traer a la palestra este crecimiento como un enfoque terapéutico adicional. Es por esta problemática que continúan explorándose nuevas estrategias y otros tratamientos que ya han mostrados resultados beneficios en otras infecciones causadas por biopelículas. Se destaca la evidencia que sustenta el uso de compuestos naturales y el uso de estrategias de formulación que permiten dirigir más selectivamente los tratamientos y aumentar su retención en la mucosa gástrica. Por tanto, el desafío será aumentar los ensayos clínicos y estudiar estos tratamientos experimentales que no solo proponen nuevos agentes y combinaciones, sino también formulaciones de vanguardia que apuntan desde inhibir la adhesión de $H$. pylori hasta la erradicación de sus biopelículas. Como esta bacteria está presente en más de la mitad de la población mundial y por ser considerada por la OMS como agente carcinógeno tipo I, es necesario continuar con la investigación y el desarrollo de nuevos agentes para la erradicación de esta infección tan prevalente.

\section{Fuentes de financiamiento}

La investigación sobre tratamiento contra infecciones causadas por biopelículas bacterianas de TB-C es auspiciada por el proyecto CONICYT PAI Convocatoria Nacional Subvención a la Instalación en la Academia, Convocatoria 2019 PAI77190010.

\section{Contribuciones y conflictos declarados por los autores}

BV y CD contribuyeron equitativamente al desarrollo de este manuscrito. TB-C contribuyó como guía y revisora del documento. Los autores agradecen a Daniel Moraga-Espinoza por su apoyo en el diseño de las figuras. Los autores no tienen conflictos de interés que declarar.

\section{Referencias}

Arenas A, Serrano C, Quiñones L, Harris P, Sandoval M, Lavanderos M, Sepúlveda R, Maquilón S, Echeverría A, Ríos C, Fuentes-López $E$, Rojas L, Jorquera A, Pizarro M, Camargo MC. \& Riquelme A. (2019). High prevalence of clarithromycin resistance and effect on Helicobacter pylori eradication in a population from Santiago, Chile: cohort study and meta-analysis. Scientific Reports 9, 20070.

Argueta EA. \& Moss SF. (2019). Treatment of Helicobacter pylori. Current Opinion in Gastroenterology 35, 544-550.

Bahamondez-Canas TF, Heersema LA. \& Smyth HDC. (2019). Current Status of In Vitro Models and Assays for Susceptibility Testing for Wound Biofilm Infections. Biomedicines 7, 34.

Cammarota G, Branca G, Ardito F, Sanguinetti M, laniro G, Cianci R, Torelli R, Masala G, Gasbarrini A, Fadda G, Landolfi R. \& Gasbarrini G. (2010). Biofilm Demolition and Antibiotic Treatment to Eradicate Resistant Helicobacter pylori: A Clinical Trial. Clinical Gastroenterology and Hepatology 8, 817-820.e813. 
Carron MA, Tran VR, Sugawa C. \& Coticchia JM. (2006). Identification of Helicobacter pylori Biofilms in Human Gastric Mucosa. Journal of Gastrointestinal Surgery 10, 712-717.

Chahuán J, Pizarro M, Díaz LA, Villalón A. \& Riquelme A. (2020). Métodos de diagnóstico para la detección de la infección por Helicobacter pylori. Gastroenterologia Latinoamericana 31, 98-106.

Chen X, Li P, Shen Y, Zou Y, Yuan G. \& Hu H. (2019). Rhamnolipid-involved antibiotics combinations improve the eradication of Helicobacter pylori biofilm in vitro: A comparison with conventional triple therapy. Microbial Pathogenesis 131, 112-119.

Coticchia JM, Sugawa C, Tran VR, Gurrola J, Kowalski E. \& Carron MA. (2006). Presence and density of Helicobacter pylori biofilms in human gastric mucosa in patients with peptic ulcer disease. Journal of Gastrointestinal Surgery 10, 883-889.

Donlan RM. \& Costerton JW. (2002). Biofilms: survival mechanisms of clinically relevant microorganisms. Clinical Microbiology Reviews 15, 167-193.

Flores-Treviño S, Mendoza-Olazarán S, Bocanegra-lbarias P, Maldonado-Garza HJ. \& Garza-González E. (2018). Helicobacter pylori drug resistance: therapy changes and challenges. Expert review of gastroenterology \& hepatology 12, 819-827.

García EC. \& García-González R. (2015). Helicobacter pylori y la respuesta inmune. Revista Mexicana de Patología Clínica y Medicina de Laboratorio 62, 112-118.

González-Hormazábal P, Arenas A, Serrano C, Pizarro M, Fuentes-López E, Arnold J, Berger Z, Musleh M, Valladares H, Lanzarini E, Jara L, Castro VG, Camargo MC. \& Riquelme A. (2021). Prevalence of Helicobacter pylori Antimicrobial Resistance Among Patients Recruited in Endoscopy Units in Santiago, Chile. Archives of Medical Research.

Gopalakrishnan V, Masanam E, Ramkumar VS, Baskaraligam V. \& Selvaraj G. (2020). Influence of N-acylhomoserine lactonase silver nanoparticles on the quorum sensing system of Helicobacter pylori: A potential strategy to combat biofilm formation. Journal of Basic Microbiology 60, 207-215.

Gottesmann M, Goycoolea FM, SteinbacherT, Menogni T. \& Hensel A. (2020). Smart drug delivery against Helicobacter pylori: pectin-coated, mucoadhesive liposomes with antiadhesive activity and antibiotic cargo. Applied Microbiology and Biotechnology 104, 5943-5957.

Hathroubi S, Zerebinski J, Clarke A. \& Ottemann KM. (2020). Helicobacter pylori Biofilm Confers Antibiotic Tolerance in Part via A Protein-Dependent Mechanism. Antibiotics 9, 355.
Holden DW. (2015). Persisters unmasked. Science 347, 30-32.

Hu Y, Zhu Y \& Lu N-H. (2020). Recent progress in Helicobacter pylori treatment. Chinese Medical Journal 133, 335-343.

Ji J. \& Yang H. (2021). In Vitro Effects of Lactobacillus plantarum LN66 and Antibiotics Used Alone or in Combination on Helicobacter pylori Mature Biofilm. Microorganisms 9, 424.

Jiang L. \& Zhu W. (2018). Probiotics improved the effectiveness and safety of the quadruple Helicobacter pylori eradication therapy. Biomedical Research 29, 2053-2056.

Kamiya S, Yonezawa H. \& Osaki T. (2019). Role of probiotics in eradication therapy for Helicobacter pylori infection. In Helicobacter pylori in Human Diseases, ed. Kamiya S \& Backert S, pp. 243-255.

Krzyżek P, Migdał P, Paluch E, Karwańska M, Wieliczko A. \& Gościniak G. (2021). Myricetin as an Antivirulence Compound Interfering with a Morphological Transformation into Coccoid Forms and Potentiating Activity of Antibiotics against Helicobacter pylori. International Journal of Molecular Sciences 22, 2695.

Leal J, Smyth HD. \& Ghosh D. (2017). Physicochemical properties of mucus and their impact on transmucosal drug delivery. International Journal of Pharmaceutics 532, 555-572.

Li P, Chen X, Shen Y, Li H, Zou Y, Yuan G, Hu P. \& Hu H. (2019). Mucus penetration enhanced lipid polymer nanoparticles improve the eradication rate of Helicobacter pylori biofilm. Journal of Controlled Release 300, 52-63.

Martínez JD, Henao SC. \& Lizarazo Jl. (2014). Resistencia antibiótica del Helicobacter pylori en América Latina y el Caribe. Revista Colombiana de Gastroenterología 29, 218-227.

Miller AK. \& Williams SM. (2021). Helicobacter pylori infection causes both protective and deleterious effects in human health and disease. Genes \& Immunity.

Ortega JP, Espino A, Calvo B A, Verdugo P, Pruyas M, Nilsen E, Villaroel L, Padilla O, Riquelme A \& Rollan A. (2010). Infección por Helicobacter pylori en pacientes sintomáticos con patología gastroduodenal benigna: Análisis de 5.664 pacientes. Revista Médica de Chile 138, 529-535.

Saracino IM, Pavoni M, Saccomanno L, Fiorini G, Pesci V, Foschi C, Piccirilli G, Bernardini G, Holton J. \& Figura N. (2020). Antimicrobial efficacy of five probiotic strains against Helicobacter pylori. Antibiotics 9, 244. 
Velasco et al.

Shah SC, lyer PG. \& Moss SF. (2021). AGA Clinical practice update on the management of refractory Helicobacter pylori infection: expert review. Gastroenterology 160, 1831-1841.

Shen Y, Li P, Chen X, Zou Y, Li H, Yuan G. \& Hu H. (2020a). Activity of Sodium Lauryl Sulfate, Rhamnolipids, and N-Acetylcysteine Against Biofilms of Five Common Pathogens. Microbial Drug Resistance 26, 290-299.

Shen Y, Zou Y, Chen X, Li P, Rao Y, Yang X, Sun Y. \& Hu H. (2020b). Antibacterial self-assembled nanodrugs composed of berberine derivatives and rhamnolipids against Helicobacter pylori. Journal of Controlled Release 328, 575-586.

Shinmura T, Adachi K, Yamaguchi Y, Izawa S, Hijikata Y, Ebi M, Funaki Y, Ogasawara N, Sasaki M. \& Kasugai K. (2019). Vonoprazan-Based Triple-Therapy Could Improve Efficacy of the Tailored Therapy of Helicobacter pylori Infection. Journal of Gastrointestinal and Liver Diseases 28, 389-395.

Suriani R, Colozza M, Cardesi E, Mazzucco D, Marino M, Grosso S, Sanseverinati S, Venturini I, Borghi A. \& Zeneroli ML. (2008). CagA and VacA Helicobacter Pylori Antibodies in Gastric Cancer. Canadian Journal of Gastroenterology 22, 521724.

Urrejola MC, Soto LV, Zumarán CC, Peñaloza JP, Álvarez B, Fuentevilla I. \& Haidar ZS. (2018). Sistemas de nanopartículas poliméricas II: estructura, métodos de elaboración, características, propiedades, biofuncionalización y tecnologías de auto-ensamblaje capa por capa (layer-by-layer self-assembly). International Journal of Morphology 36, 1463-1471.
Villalón A, Reyes D, Ortiz J, Gándara V, Díaz L, Chahuán J, Pizarro M. \& Riquelme A. (2020). Treatment and management of Helicobacter pylori infection. Gastroenterologia Latinoamericana 31, 136-146.

Yang JY, Kim J-B, Lee P. \& Kim S-H. (2021). Evodiamine Inhibits Helicobacter pylori Growth and Helicobacter pylori-Induced Inflammation. International Journal of Molecular Sciences 22, 3385.

Yang S-J, Huang C-H, Yang J-C, Wang C-H. \& Shieh M-J. (2020). Residence Time-Extended Nanoparticles by Magnetic Field Improve the Eradication Efficiency of Helicobacter pylori. ACS Applied Materials \& Interfaces 12, 54316-54327.

Yonezawa H, Osaki T, Hanawa T, Kurata S, Ochiai K. \& Kamiya S. (2013). Impact of Helicobacter pylori biofilm formation on clarithromycin susceptibility and generation of resistance mutations. PloS one 8, e73301-e73301.

Yu M, Zhang R, Ni P, Chen S. \& Duan G. (2019). Efficacy of Lactobacillus-supplemented triple therapy for $\mathrm{H}$. pylori eradication: $\mathrm{A}$ meta-analysis of randomized controlled trials. PloS one 14, e0223309.

Zhao S, Lv Y, Zhang J-B, Wang B, Lv G-J. \& Ma X-J. (2014). Gastroretentive drug delivery systems for the treatment of Helicobacter pylori. World Journal of Gastroenterology 20, 9321-9329. 